\title{
Management of Acute Lower Gastrointestinal Bleeding: Principles and Current Practice in the United Kingdom
}

\author{
James Robins, ${ }^{1}$ Anne Shrestha, ${ }^{2}$ James Hampton, ${ }^{3}$ Badri Man Shrestha ${ }^{1}$ \\ 'Department of General Surgery, Sheffield Teaching Hospitals NHS Trust, Sheffield, UK, ${ }^{2}$ Stepping Hill Hospital, Stockport, \\ UK, ${ }^{3}$ Department of Radiology, Sheffield Teaching Hospitals NHS Trust, Sheffield, UK,
}

\begin{abstract}
Acute lower gastrointestinal bleeding (ALGIB) is a common cause for hospital admission that results in significant morbidity and mortality. The major objectives of all involved in the management of ALGBI patients are to reduce mortality and the need for major surgery. A secondary objective is to prevent unnecessary hospital admission for patients presenting with bleeding that is not lifethreatening. The management of ALGBI has evolved over last decade with the changing modalities of diagnostic facilities. On review of the published literature, there is paucity of randomised control trials in relation to the diagnostic tools and management of ALGBI. The aim of this review is to summarise the principles and current methods available for the diagnosis and treatment of ALGIB and based on the available evidence and the current practice in the United Kingdom, outline an algorithm for the management of ALGIB.
\end{abstract}

Keywords: Lower gastrointestinal bleeding; aetiology; prognosis; management algorithm.

\section{INTRODUCTION}

Acute lower gastrointestinal bleeding (ALGIB) is a common cause for hospital admission that results in significant morbidity and mortality. The bleeding emanates from a source distal to the ligament of Treitz; that is of recent duration, arbitrarily defined as less than three days' duration, which may range from trivial to massive, life-threatening blood loss resulting in instability of vital signs, anaemia, and/or the need for blood transfusion. ${ }^{1} \quad$ Bleeding from the lower gastrointestinal (GI) tract may account for up to $25 \%$ of all acute GI bleeding and one third of GI bleed-related hospital admissions. Although $80-85 \%$ of patients have a self-limiting lower ALGIB and an uncomplicated hospitalization, the reported mortality rate ranges from $2 \%$ to $4 \% .^{2}$

The major objectives of all involved in the management of bleeding patients are to reduce mortality and the need for major surgery. A secondary objective is to prevent unnecessary hospital admission for patients presenting with bleeding that is not life threatening. ${ }^{3}$ After initial resuscitation of the patient, the diagnosis and treatment of lower gastrointestinal bleeding remains a challenge for acute care surgeons. Identifying the source of bleeding can be difficult since many patients bleed intermittently or stop bleeding spontaneously. It is therefore important for the acute care surgeon to be familiar with the different diagnostic and therapeutic modalities and their advantages and disadvantages in order to guide the management of the acutely bleeding patient. $^{4}$

The aim of this review is to summarise the principles and current methods available for the diagnosis and treatment of ALGIB and based on the available evidence and the current practice in the United Kingdom, outline an algorithm on the management of ALGIB.

\section{LITERATURE SEARCH STRATEGY}

In our review, we searched articles in PubMed using

Correspondence: BM Shrestha MD FRCS, Department of General Surgery, Northern General Hospital, Sheffield S5 7AU, UK. Email: shresthabm@doctors.net.uk, Fax+441142714604 
J et al. Management of Acute Lower Gastrointestinal Bleeding: Principles and Current Practice in the United Kingdom

the MeSH words "lower gastrointestinal bleeding" in combination with " management", "CT angiography", "colonoscopy", "enteroscopy", "capsule endoscopy", "embolization" and "surgery". Relevant references were compiled using the EndNote software (X 7.4; Thomson Reuters, Philadelphia, PA, USA).

\section{AETIOLOGY OF ALGIB}

The incidence of ALGIB is estimated to be 20.5 cases per 100000 across both genders with a male incidence of 24.2 compared with a female incidence of 17.2. There is an increased incidence of 200-fold amongst individuals in their $9^{\text {th }}$ decade compared to those in their $3^{\text {rd }}$ decade of life. ${ }^{5}$ The Table 1 summarises the causes of ALGIB from studies with $n>100$, based on a review by Zuckerman and Prakesh. ${ }^{6}$ Rectal examination in patients presenting with haematochezia is essential to detect ongoing bleeding and enable diagnosis of local anorectal conditions (accounting for $14 \%$ of acute ALGIB). ${ }^{3}$ ALGIB is more common than upper among patients on dual antiplatelet therapy (74\% lower vs. $26 \%$ upper). ${ }^{7}$ Small bowel sources account for 0.7 $9.0 \%$ of cases of severe haematochezia. ${ }^{2}$

\begin{tabular}{|ll|}
\hline $\begin{array}{l}\text { Table 1. Causes of acute } \\
\text { bleeding }\end{array}$ & Mewer gastrointestinal \\
\hline Cause & 35.33 (15-55) \\
Diverticulosis & $6.50(3-12)$ \\
Angiodysplasia & 17.33 (8-36) \\
$\begin{array}{l}\text { Neoplasia (Cancer/Polyp) } \\
\text { Colitis (Chronic inflammatory } \\
\text { bowel disease, ischaemic, } \\
\text { infectious, radiation-induced, } \\
\text { vasculitis and idiopathic) }\end{array}$ & 15.00 (6-22) \\
$\begin{array}{l}\text { Anorectal (haemorrhoids, anal } \\
\text { fissure, rectal ulcers). }\end{array}$ & 4.17 (0-9) \\
$\begin{array}{l}\text { Other (post-polypectomy } \\
\text { bleeding, aortocolonic fistula, } \\
\text { faecal impaction trauma and } \\
\text { anastomotic bleeding) }\end{array}$ & 7.17 (3-14) \\
Unknown & $14.67(1-25)$ \\
\hline
\end{tabular}

\section{RISK FACTORS FOR ALGIB}

The available evidence identifies the following factors are associated with uncontrolled bleeding and/or death. Acute haemodynamic disturbance (OR 3 to 4.3) and gross rectal bleeding on initial examination (OR 2.3 to 3) are important predictors of subsequent severe bleeding. ${ }^{8}$ The presence of two co-morbid conditions doubles the chance of a severe bleed (OR 1.9). Patients taking aspirin or non-steroidal anti-inflammatory drugs are at increased risk of severe lower ALGIB (OR 1.8 to 2.7).9,10 Patients hospitalised for another condition and who subsequently bleed after admission have a mortality rate of $23 \%$ compared with $3.6 \%$ in those admitted to hospital because of rectal bleeding $(p<0.001)^{2,9,11}$

\section{PRINCIPLES OF MANAGEMENT OF ALGIB}

\section{A. INITIAL RESUSCITATION AND APPRAISAL}

In the majority of UK hospitals patients with upper GI bleeds are admitted to general medical wards and patients with ALGIB are admitted to surgical units. As in any emergency, attention should be paid to maintain oxygenation to vital organs by maintaining normovolaemia by infusions and blood transfusions followed by investigations to localise the site of bleeding. All patients with rectal bleeding should have a full history taken, abdominal examination and should undergo digital rectal examination, proctoscopy and rigid sigmoidoscopy initially to exclude anorectal disease such as haemorrhoids or anal fissure. Table 2 shows a commonly adopted general guidance for triage of patients with ALGIB. ${ }^{3}$

Table 2. Initial assessment protocol

Consider for discharge or non-admission with outpatient follow up if:

- age $<60$ years, and;

- no evidence of haemodynamic compromise, and;

- no evidence of gross rectal bleeding, and;

- an obvious anorectal source of bleeding on rectal examination/sigmoidoscopy.

Consider for admission if:

- age $\geq 60$ years, or

- haemodynamic disturbance, or;

- evidence of gross rectal bleeding, or;

- taking aspirin or an NSAID, or;

- significant comorbidity.

\section{LOCALISATION OF THE SOURCE OF BLEEDING}

It is important to establish the location of ALGIB, although in up to $10 \%$ of cases, the origin of the bleed, despite rigorous investigations, is not identifiable. ${ }^{12}$ The insertion of a nasogastric tube and aspirating for the presence of blood is a simple way of excluding a high upper gastrointestinal bleed. ${ }^{13}$ With conservative management, ALGIB stops spontaneously in $80 \%$ of cases, and re-bleeding occurs in $25 \%$ of cases supporting the requirement for active intervention. ${ }^{14}$

In haemodynamically stable patients, an urgent oesophagogastroduodenoscopy (OGD) is performed to exclude an upper GI source of bleeding. On the other hand in actively bleeding and haemodynamically unstable patients, in conjunction with resuscitation 
J et al. Management of Acute Lower Gastrointestinal Bleeding: Principles and Current Practice in the United Kingdom

and blood transfusion, an emergency computerised tomographic (CT) angiography is performed to localise the site of bleeding. If extravasation of contrast is visualised in the bowel lumen, either embolization of the bleeding artery or a surgical resection is undertaken. In patients, where bleeding has stopped, a colonoscopy is performed after adequate bowel preparation, which may identify a possible source of bleeding. Failing to localise the source of bleeding on above-mentioned investigations, mandates investigation of the small intestine with capsule endoscopy, nuclear scintigraphy or enteroscopy in an elective basis. The quantity of evidence on which this practice is based is limited. Few studies have compared diagnostic modalities, which are discussed individually.

\section{Computerised Tomographic angiography}

Multidetector computed tomographic (CT) angiography with its speed, resolution, multiplanar techniques, and angiographic capabilities allows excellent visualization of both the small and large bowel. ${ }^{15}$ It is particularly useful in the investigation of angiodysplasia, with a sensitivity of $70 \%$ and specificity of $100 \% .{ }^{16}$ It is widely considered to be a sensitive, specific, well tolerated and minimally invasive investigation and has replaced conventional angiography for diagnosis of an acute massive bleed (Figure 1). ${ }^{17}$
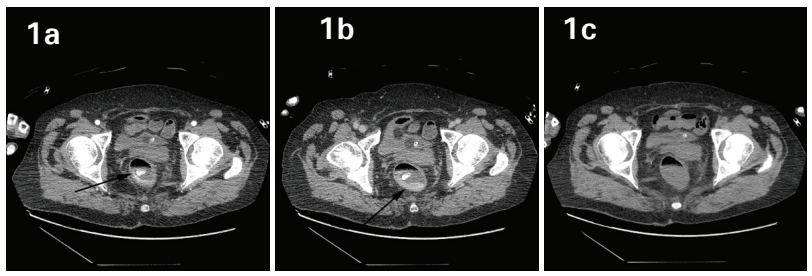

Figure 1. Acute bleeding into the rectum is seen on CT angiography as high density contrast in the lumen of the rectum in the arterial phase (arrow) in figure $1-a$. There is progressive accumulation of contrast in the dependent part of the rectum in the venous phase (arrow) in figure 1-b. No contrast was seen in the lumen on the pre-contrast scan, figure 1-c.

\section{Conventional Angiography}

Conventional angiography through femoral artery still has a role to play in diagnosis of ALGIB in haemodynamically unstable patients. ${ }^{18}$ Angiography examines the superior and inferior mesenteric arteries and coeliac trunks and their branches to exclude the source of bleeding. Angiography has a sensitivity of $47-65 \%$ in an acute haemorrhage and a specificity of $100 \% .{ }^{19,20}$ The extravasation of contrast into the lumen of the intestine corresponds to the site of bleeding. At present, conventional angiography is used for embolization of the bleeding artery, after a bleeding is demonstrated in CT angiography ${ }^{21}$ (Figure 2).
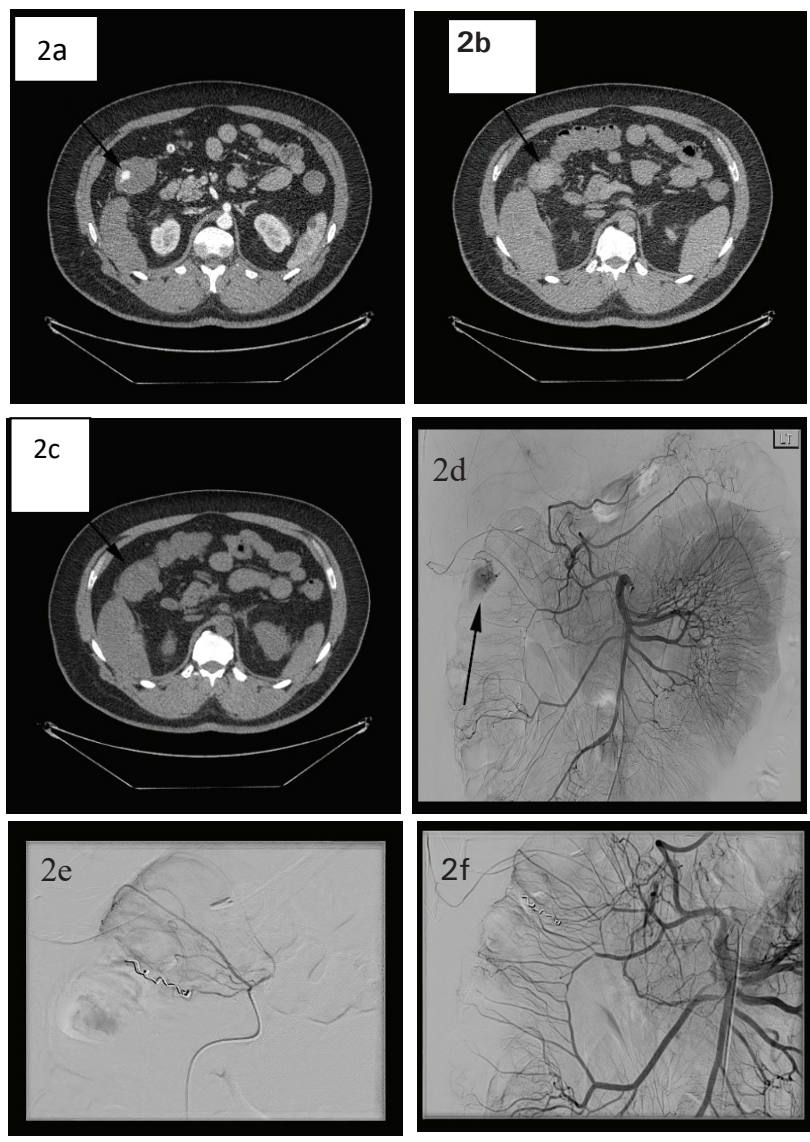

Figure 2. CT angiogram showing acute bleeding the hepatic flexure of the colonic lumen on the arterial phase scan (arrow, figure 2-a). There remains some slightly high density contrast in the lumen on the venous phase scan (arrow, figure 2-b). No abnormality was seen in the same area on the pre-contrast scan (figure 2-c). The patient was transferred to the angiography suite, where active bleeding was demonstrated as contrast extravasation into the bowel lumen (arrows, figures 2-d). No bleeding was seen following coil embolization and the patient's condition stabilised (figures 2-e, f).

\section{Colonoscopy}

The role of urgent colonoscopy in ALGIB remains controversial. Although some studies have shown that examinations performed within 12-24 h of admission improve diagnostic yield and reduce re-bleeding and surgery, others have not. A source of bleeding can be identified in $8-34 \%$ of patients who undergo urgent colonoscopy for management of ALGIB. ${ }^{22,23}$ Cleansing the colon rapidly can be achieved either by hydrofulsh or through-the scope purge preparation methods. ${ }^{24,25}$

Laine and Shah had reported a randomized trial of urgent ( $<12 \mathrm{~h}$ from admission) vs. elective (36-60 $\mathrm{h}$ from admission) colonoscopy in 72 patients with 
ALGIB. A total of $15 \%$ of patients with presumed ALGIB were found to have upper gastrointestinal bleeding, highlighting the importance of excluding a gastroduodenal source in patients with severe haematochezia. The majority of patients with ALGIB (72\%) stopped bleeding spontaneously, and there were no differences in re-bleeding, blood transfusions, diagnostic or therapeutic interventions, length of hospital stay, or hospital charges in patients undergoing urgent vs. elective colonoscopy. ${ }^{23}$

\section{Enteroscopy}

Double balloon enteroscopy (DBE) enables visualisation of the entire small bowel and provides biopsy and therapeutic intervention opportunities is considered to be a useful investigation in the diagnosis of gastrointestinal bleeds of obscure origin. ${ }^{26} 27,28$ It has been reported to have a diagnostic yield of $64 \%$ in one study and $74 \%$ in another, and the latter reported a treatment success rate of $91 \% .^{26,29}$ The completion rate of DBE has been reported as $16-86 \% .{ }^{30,31}$

\section{Video Capsule Endoscopy}

Video Capsule endoscopy is mainly indicated in cases of obscure gastrointestinal bleeding, particularly to locate bleeding from small intestine; however it has also been used for investigation of Crohn's disease, Coeliac disease and small intestine tumours and in up to $80 \%$ of cases the entire small bowel can be examined. ${ }^{32}$

\section{Barium enema}

The role of barium enema in the management of acute ALGIB is limited to the diagnosis of diverticular disease or neoplasia in an elective setting but by no means would confirm the source of bleeding. ${ }^{33}$

\section{Nuclear scintigraphy}

Nuclear scintigraphy by utilising red blood cells labelled with Technetium-99m is helpful in the localisation of the source of bleeding in cases where other modalities of investigations have failed. In one study the diagnosis of the source of bleeding by nuclear imaging was confirmed in $75 \%$ of patients who went on to have surgery, of which $86 \%$ had a positive scan within 2 hours. ${ }^{34}$

\section{A. TREATMENT OF ALGIB}

\section{Endoscopic methods}

Bleeding lesions accessible through endoscopes are dealt with employing following techniques:
For haemorrhage from haemorrhoids and rectal varices, the use of rubber bands is effective. It is important however to ensure that the amount of tissue suctioned prior to band ligation is checked to prevent full thickness tissue entrapment increasing perforation risk. ${ }^{33}$

\section{Thermal coagulation}

Haemostasis may be achieved by simple monopolar or bipolar cautery where a low potential difference enables a current to flow through an angiodysplastic lesions. However, thermal coagulation carries a perforation risk of $2.5 \%$ in the thinnest section, the right hemicolon, where angiodysplasia is common. ${ }^{35,36}$

\section{Argon plasma coagulation}

The argon plasma coagulator (APC) delivers monopolar energy without touching the luminal wall using argon gas. APC is found to be safe and effective in treating bleeding vascular lesions in the intestine. The key advantage is that the perforation risk reported is virtually $0 \% \cdot{ }^{35,37,38}$

\section{Laser coagulation}

Laser coagulation works by high energy leading to tissue vaporisation, however confining the penetration of the laser is difficult, in particular with the Nd:YAG laser and thus there is higher perforation risk, but has higher efficacy compared to other endoscopic treatment methods. ${ }^{38,39}$

\section{Sclerotherapy}

In lower gastrointestinal bleeds, sclerotherapy only currently involves the injection of 1:10000 adrenaline into the submucosa over several locations. In diverticula, injection is done around the orifice. The vasoconstrictive effect with possibly also an effect of tamponade, usually successfully achieves only a temporary haemostasis. ${ }^{35}$

\section{Interventional angiography \\ Intra-arterial vasopressin injection}

Intra-arterial vasopressin into selective mesenteric arteries has an initial bleed control of $62-100 \%$, but this seems to be only an effective short-term solution as the re-bleed rates are $16-50 \%$. Minor complications such as fluid retention and hyponatraemia occur in up to $41 \%$, and major complications such as pulmonary oedema and myocardial ischaemia in $21 \%$ of patients are reported. ${ }^{40}$ As a result of the high complication rate, this therapy is now only used in exceptional circumstances.

\section{Mechanical devices}




\section{Transcatheter embolisation}

Smaller microcatheters enabling more distal embolisation combined with new embolising agents such as microcoils, gelfoam and polyvinyl alcohol particles have resulted in major ischemic complication-free success rates of $70-90 \% .{ }^{41}$ The re-bleed rate is reported as being around $15 \%$, however in angiodysplasia this can be as high as $40 \%$. Generally the right colon and caecum are easier to embolise than the left colon. It is recommended that transcatheter embolisation is performed in haemodynamically unstable patients unsuitable for colonoscopy, or colonoscopy patients in whom no source was found. ${ }^{33}$

\section{Surgical interventions}

Surgery used to be the mainstay of treatment in the past, which is now indicated only in neoplastic causes and haemodynamically unstable patients with a persistent bleed that has failed to respond to transcatheter embolisation. ${ }^{33,42}$ The approach is to perform a segmental resection of the bleeding area e.g. a left hemicolectomy. ${ }^{42,43}$ Subtotal colectomy performed in cases of unidentified source of bleeding carries a re-bleed rate of up to $75 \%$ with a $50 \%$ mortality suggesting intraoperative colonoscopy would be beneficial to localise a source. ${ }^{33}$ Segmental resections appear to have a varied mortality from 16$40 \%$ and morbidity of $6-60 \% .{ }^{44}$ However these are reduced when surgery follows a staged diagnostic approach on a localised bleed. ${ }^{45}$

\section{ALGORITHM OF THE MANAGEIMENT OF ALGB}

Based on the available evidence, the following algorithm for the management of ALGBI is outlined (Figure 3).

\section{PROGNOSIS OF ALGIB}

The overall mortality in patients admitted to hospital with ALGIB is reported to be between 0.6-2.4\%. ${ }^{5,46}$ The diverticular aetiology is a poor prognostic predicting factor, particularly compared to angiodysplasia bleeds with a mortality of $4 \%$ at 3 years. ${ }^{5,47}$

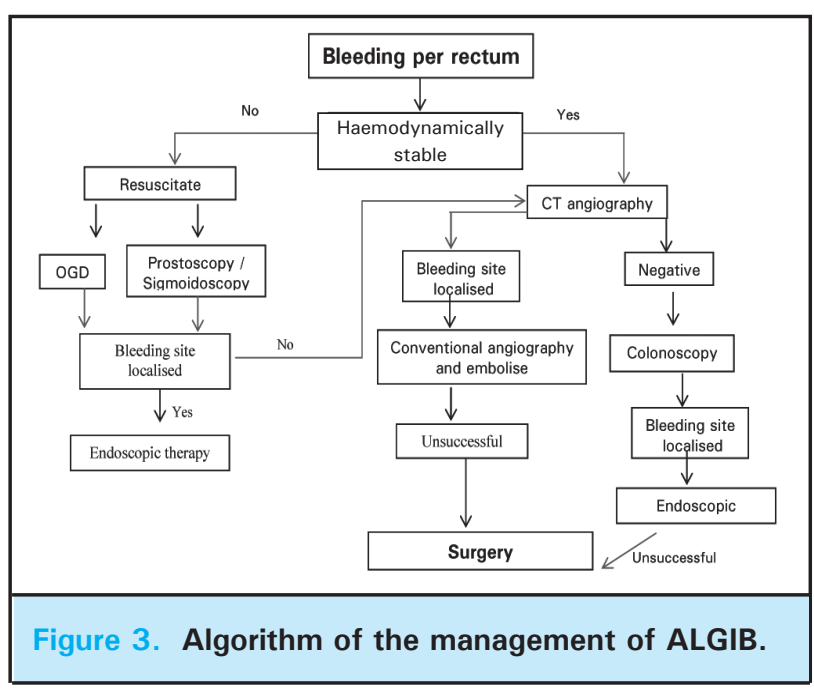

Although $\mathrm{Gl}$ events in the small bowel are less frequent than those in upper or lower GI tract, they are the most severe and are associated with higher risks of mortality and hospital readmissions. ${ }^{48}$ Early colonoscopy to determine the appearance of the bleeding tissue has been identified as an accurate predictor of outcome. The presence of a visibly bleeding vessel or adherent clot is a reliable marker for differentiation between significant and insignificant haemorrhage $(p<0.006){ }^{49,50}$

\section{CONCLUSION}

ALGIB is a common surgical emergency, which mandates appropriate management because of associated mortality. Appreciation of the efficacy of individual modality of investigation and treatment is paramount, which should be tailed to individual patient's need. Organisation of a round the clock service and an effective protocol is vital in reducing the hospital stay and mortality.

\section{REFERENCES}

1. Barnert J, Messmann H. Diagnosis and management of lower gastrointestinal bleeding. NatRevGastroenterolHepatol 2009; 6(11): 637-46.

2. Farrell JJ, Friedman LS. Gastrointestinal bleeding in the elderly. Gastroenterology clinics of North America 2001; 30(2): 377-407, viii.

3. Scottish Executive. Scottish Referral Guidelines for Suspected Cancer. Edinburgh: Scottish Executive; 2007. (ref. NHS HDL(2007)09). Available from http://www.sehd.scot.nhs. uk/mels/HDL2007_09.pdf: [Accessed. 30 December 2015].
4. Pant C, Olyaee M, Sferra TJ, Gilroy R, Almadhoun O, Deshpande A. Emergency department visits for gastrointestinal bleeding in children: results from the Nationwide Emergency Department Sample 2006-2011. Curr Med Res Opin 2015; 31(2): 347-51

5. Longstreth GF. Epidemiology and outcome of patients hospitalized with acute lower gastrointestinal hemorrhage: a population-based study. Am J Gastroenterol 1997; 92(3): 419-24.

6. Zuckerman GR, Prakash C. Acute lower intestinal bleeding. Part II: etiology, therapy, and outcomes. Gastrointest Endosc 1999; 49(2): 228-38. 
7. Casado Arroyo R, Polo-Tomas M, Roncales MP, Scheiman J, Lanas A. Lower GI bleeding is more common than upper among patients on dual antiplatelet therapy: long-term follow-up of a cohort of patients commonly using PPI co-therapy. Heart 2012; 98(9): 718-23.

8. Velayos FS, Williamson A, Sousa KH, et al. Early predictors of severe lower gastrointestinal bleeding and adverse outcomes: a prospective study. ClinGastroenterolHepatol 2004; 2(6): 485-90.

9. Strate LL, Syngal S. Timing of colonoscopy: impact on length of hospital stay in patients with acute lower intestinal bleeding. AmJGastroenterol 2003; 98(2): 317-22.

10. Yong D, Grieve P, Keating J. Do nonsteroidal anti-inflammatory drugs affect the outcome of patients admitted to hospital with lower gastrointestinal bleeding? The New Zealand medical journal 2003; 116(1178): U517.

11. Longstreth GF. Epidemiology and outcome of patients hospitalized with acute lower gastrointestinal hemorrhage: a population-based study. AmJGastroenterol 1997; 92(3): 419-24.

12. Jensen DM, Machicado GA. Diagnosis and treatment of severe hematochezia. The role of urgent colonoscopy after purge. Gastroenterology 1988; 95(6): 1569-74.

13. Edelman DA, Sugawa C. Lower gastrointestinal bleeding: a review. SurgEndosc 2007; 21(4): 514-20.

14. Lee J, Costantini TW, Coimbra R. Acute lower GI bleeding for the acute care surgeon: current diagnosis and management. Scandinavian journal of surgery : SJS : official organ for the Finnish Surgical Society and the Scandinavian Surgical Society 2009; 98(3): 135-42.

15. Quiroga GS, Perez LM, Abu-Suboh AM, Castell CJ. Gastrointestinal bleeding: the role of radiology. Radiologia 2011; 53: 406-20.

16. Junquera F, Quiroga S, Saperas E, et al. Accuracy of helical computed tomographic angiography for the diagnosis of colonic angiodysplasia. Gastroenterology 2000; 119(2): 293-9.

17. Ghassemi KA, Jensen DM. Lower GI bleeding: epidemiology and management. Current gastroenterology reports 2013; 15(7): 333 .

18. Peynircioglu B, Erkus F, Cil B, Ciftci T, Durhan G, Balkanci F. Mesenteric angiography of patients with gastrointestinal tract hemorrhages: a single center study. DiagnIntervRadiol 2011.

19. Leitman IM, Paull DE, Shires GT, 3rd. Evaluation and management of massive lower gastrointestinal hemorrhage. Ann Surg 1989; 209(2): 175-80.

20. Fiorito JJ, Brandt LJ, Kozicky O, Grosman IM, Sprayragen $\mathrm{S}$. The diagnostic yield of superior mesenteric angiography: correlation with the pattern of gastrointestinal bleeding. Am J Gastroenterol 1989; 84(8): 878-81.

21. Zuckerman DA, Bocchini TP, Birnbaum EH. Massive hemorrhage in the lower gastrointestinal tract in adults: diagnostic imaging and intervention. AJR Am J Roentgenol 1993; 161(4): 703-11.
22. Green BT, Rockey DC, Portwood G, et al. Urgent colonoscopy for evaluation and management of acute lower gastrointestinal hemorrhage: a randomized controlled trial. AmJGastroenterol 2005; 100(11): 2395-402.

23. Laine L, Shah A. Randomized trial of urgent vs. elective colonoscopy in patients hospitalized with lower GI bleeding. The American journal of gastroenterology 2010; 105(12): 2636-41; quiz 42.

24. Penfield JD, Abu Dayyeh BK, Baron TH. A novel through-the-scope purge preparation for active lower GI bleeding. The American journal of gastroenterology 2013; 108(6): 1017-8.

25. Repaka A, Atkinson MR, Faulx AL, et al. Immediate unprepared hydroflush colonoscopy for severe lower GI bleeding: a feasibility study. Gastrointestinal endoscopy 2012; 76(2): 367-73

26. Manabe N, Tanaka S, Fukumoto A, Nakao M, Kamino D, Chayama K. Double-balloon enteroscopy in patients with GI bleeding of obscure origin. Gastrointest Endosc 2006; 64(1): 135-40.

27. Keum B, Chun HJ. Capsule endoscopy and double balloon enteroscopy for obscure gastrointestinal bleeding: which is better? J Gastroenterol Hepatol 2011; 26(5): 794-5.

28. Pasha SF, Hara AK, Leighton JA. Diagnostic evaluation and management of obscure gastrointestinal bleeding: a changing paradigm. Gastroenterol Hepatol (N Y) 2009; 5(12): 839-50.

29. Arakawa D, Ohmiya N, Nakamura M, et al. Outcome after enteroscopy for patients with obscure GI bleeding: diagnostic comparison between double-balloon endoscopy and videocapsule endoscopy. Gastrointest Endosc 2009; 69(4): 866-74.

30. Gross SA, Stark ME. Initial experience with double-balloon enteroscopy at a U.S. center. Gastrointestinal endoscopy 2008; 67(6): 890-7.

31. Yamamoto H, Sekine Y, Sato Y, et al. Total enteroscopy with a nonsurgical steerable double-balloon method. Gastrointestinal endoscopy 2001; 53(2): 216-20.

32. Gerson LB, Fidler JL, Cave DR, Leighton JA. ACG Clinical Guideline: Diagnosis and Management of Small Bowel Bleeding. The American journal of gastroenterology 2015; 110(9): 1265-87; quiz 88.

33. Barnert J, Messmann H. Diagnosis and management of lower gastrointestinal bleeding. Nat Rev Gastroenterol Hepatol 2009; 6(11): 637-46.

34. Dusold R, Burke K, Carpentier W, Dyck WP. The accuracy of technetium-99m-labeled red cell scintigraphy in localizing gastrointestinal bleeding. Am J Gastroenterol 1994; 89(3): 345-8.

35. Whitlow CB. Endoscopic treatment for lower gastrointestinal bleeding. Clin Colon Rectal Surg 2010; 23(1): 31-6.

36. Foutch PG. Angiodysplasia of the gastrointestinal tract. Am J Gastroenterol 1993; 88(6): 807-18.

37. Whitlow CB. Endoscopic treatment for lower gastrointestinal bleeding. ClinColon RectalSurg 2010; 23(1): 31-6. 
38. Swain CP. Laser therapy for gastrointestinal bleeding. Gastrointestinal endoscopy clinics of North America 1997; 7(4): 611-39.

39. Kwan V, Bourke MJ, Williams SJ, et al. Argon plasma coagulation in the management of symptomatic gastrointestinal vascular lesions: experience in 100 consecutive patients with long-term follow-up. AmJGastroenterol 2006; 101(1): 58-63.

40. Sherman LM, Shenoy SS, Cerra FB. Selective intra-arterial vasopressin: clinical efficacy and complications. Ann Surg 1979; 189(3): 298-302.

41. Farrell JJ, Friedman LS. Review article: the management of lower gastrointestinal bleeding. Aliment Pharmacol Ther 2005; 21(11): 1281-98.

42. Klar E, Stowhas M, Foitzik T. [A surgical approach to acute intestinal bleeding]. Chirurg 2006; 77(2): 133-8.

43. Czymek R, Kempf A, Roblick UJ, et al. Surgical treatment concepts for acute lower gastrointestinal bleeding. J Gastrointest Surg 2008; 12(12): 2212-20.

44. Czymek R, Kempf A, Roblick U, et al. Factors predicting the postoperative outcome of lower gastrointestinal hemorrhage. Int J Colorectal Dis 2009; 24(8): 983-8.
45. Schilling MK, Scheurer U, Buchler MW. [Lower gastrointestinal hemorrhage: etiologic assessment and surgical concept]. Zentralbl Chir 1998; 123(12): 1400-4.

46. Kollef MH, O'Brien JD, Zuckerman GR, Shannon W. BLEED: a classification tool to predict outcomes in patients with acute upper and lower gastrointestinal hemorrhage. Crit Care Med 1997; 25(7): 1125-32.

47. Gupta N, Longo WE, Vernava AM, 3rd. Angiodysplasia of the lower gastrointestinal tract: an entity readily diagnosed by colonoscopy and primarily managed nonoperatively. Dis Colon Rectum 1995; 38(9): 979-82.

48. Rahme E, Roussy JP, Woolcott J, Nedjar H, Barkun A. Mortality and readmission rates after hospitalization for upper and lower gastrointestinal events in Quebec, Canada. J Clin Gastroenterol 2013; 47(7): 586-92.

49. Foutch PG. Diverticular bleeding: are nonsteroidal anti-inflammatory drugs risk factors for hemorrhage and can colonoscopy predict outcome for patients? Am J Gastroenterol 1995; 90(10): 1779-84.

50. Strate LL, Syngal S. Timing of colonoscopy: impact on length of hospital stay in patients with acute lower intestinal bleeding. Am J Gastroenterol 2003; 98(2): 317-22. 